\title{
POR UM CLICK: NOTAS DE UMA PESQUISA DE CAMPO SOBRE O EMPREGO DOMÉSTICO NO RECIFE
}

\author{
Virgínia Areias Pereira ${ }^{12}$
}

\section{Apresentação}

A experiência que será aqui relatada é fruto de uma reflexão sobre o trabalho doméstico remunerado na cidade do Recife, tema de minha dissertação de mestrado. A escolha do objeto certamente reflete inquietações forjadas, em algum nível, a partir de duas experiências elementares: a convivência intensiva com as profissionais desde os idos de minha infância, e a literatura a que tive acesso em minha trajetória de vida que, de diferentes modos, remetia às minhas próprias vivências no que diz respeito às relações entre patrões/patroas e empregadas (os) domésticas (os): Hesse, Dostoievski, Lispector, Freyre, Lobato, entre muitos outros.

As inquietações a que me referi se encontravam (e continuam sendo) estreitamente associadas a duas constatações empíricas. Uma delas, reafirmada por alguns estudiosos (Franco, 1997; Freyre, 1967; Graham, 1992), é o evidente menosprezo pelo trabalho braçal em nossa sociedade, tecido, em boa medida, por um imaginário alimentado por longos séculos de escravidão institucionalizada no país. A outra diz respeito à percepção das ambivalências fortemente presentes nas relações que se desenvolvem no emprego doméstico. Refiro-me ao compromisso formal e aos laços afetivos, as vivências marcadas pela intimidade e pelo distanciamento, afetividades que eram incapazes de atenuar as demarcações típicas de classes.

Toda a inspiração que conduziu os primeiros esboços esteve associada a uma memória afetiva construída desde a infância, tempo em que vivenciava mais intensivamente o contato com as trabalhadoras envolvidas em cuidados e afetos. Portanto, a escolha da profissão e o delineamento do meu projeto de formação de pósgraduada em antropologia, guarda estreita relação com essa memória e as possibilidades

\footnotetext{
${ }^{1}$ Universidade Federal de Pernambuco, Brasil.

2 Doutoranda no Programa de Pós-Graduação da Universidade Federal de Pernambuco virginia.areias@gmail.com. Tutora na modalidade de Ensino à Distância pelo Programa da UAB Universidade Aberta do Brasil - no IFPE - Instituto Federal de Educação, Ciência e Tecnologia de Pernambuco.
} 
que me foram abertas por esse campo do conhecimento, a antropologia, que se alicerça em sua paixão pela diferença (Moore, 1994).

Entretanto, foi exatamente a consciência de uma memória afetiva e da estreita relação com o meu objeto de estudo que se colocou como primeiro desafio para mim. $\mathrm{O}$ que investigar daquilo que já me parecia tão conhecido? Como ver um mundo diário como um estranho, nas palavras de Damatta (1987)? Nas análises do referido autor, tal desafio consiste fundamentalmente em superar o que é familiar ou transformar o "familiar em exótico", para que o campo possa "aparecer". Trata-se a meu ver de um "olhar encantado", como lança um observador curioso diante de um universo "secreto".

Embora, em princípio, não haja nenhum impedimento ético ou obstáculo epistemológico que impossibilite o estudo daquilo sobre o que cremos ter uma noção precisa, Damatta (1987: 162) esclarece:

[...] para que o familiar possa ser percebido antropologicamente, ele tem que ser de algum modo transformado no exótico. Do mesmo modo que insisto na transformação do exótico no familiar para que possamos ter uma análise verdadeiramente sociológica. É claro que existem dificuldades em cada um desses processos de transformação, mas quando falo em familiaridade, utilizo a noção como um modo de conduzir a reflexão para a dúvida, no sentido preciso de se fazer perguntar: tudo que me é familiar é meu conhecido?

(Damatta, 1987: 162)

Reforcei então uma atitude que se agasalhava na ideia de que "nem tudo que me é familiar é necessariamente meu conhecido". Este movimento, discutido pelo autor, é importante porque, em última análise, refere-se à "familiarização do estranho" e ao "estranhamento do familiar" como recurso para "permitir a compreensão em profundidade do discurso, sua gênese e suas incidências, conservando-se ao mesmo tempo, uma posição mais distanciada do que permitiria uma posição de simpatia" (Alami, 2010: 91).

Portanto, não se trata de um processo de exotização, no sentido de abstrair a dimensão humana constante nas diferenças ou, noutras palavras, da subtração do que temos em comum enquanto espécie ou, ainda, da eliminação daquilo que nos "conecta" ou nos aproxima. Processo que, como bem argumenta Kuper (2002), só conduziria à distinção pela distinção, verdadeiro risco para as sociedades humanas. Pois a distinção pela distinção, além de danosa, pode instaurar o espaço para um relativismo absoluto e complacente. (Souza, 2012). 
Damatta (1987) se refere, antes, a uma postura metodológica quando trata o familiar/exótico de modo dinâmico, como algo que pode ser transformado ou transcendido, para que o trabalho de campo possa se realizar. Para mim, ficou a lição da perspectiva. Colocar-me como observadora consciente de minhas limitações diante de tramas em que, em diferentes níveis e modos, estive (e me encontro) inserida, representava a chave da verdadeira motivação para ver, ouvir e captar os anseios, as visões e os conflitos vivenciados pelos sujeitos implicados na relação.

\section{O objeto: aspectos gerais e algumas delimitações}

As relações entre patrões/patroas e empregadas domésticas ${ }^{3}$ também apresenta algumas particularidades. Ao contrário dos vínculos racionalistas, institucionalizados e formais, mais frequentemente presentes em outras modalidades, os pactos (tácitos ou expressos) que se estabelecem nesta esfera vão muitas vezes além do compromisso formal e se inscrevem nos domínios da afetividade, numa convivência diferenciada, assinalada por ambivalências.

As afetividades, como argumenta Sennett (2001), são construídas pelas emoções e, portanto, são intrinsecamente instáveis. Assim, sentimentos de inveja, frustração, indignação, cuidados e bem querer, invariavelmente se embaralham e são frequentes nas falas das trabalhadoras. O depoimento de uma das profissionais entrevistadas, à época, torna-se emblemático para esta discussão:

Estou aqui há mais de três anos e ela (a patroa) ainda não paga meus direitos. Não ganho salário (mínimo) e nunca tirei férias para não deixá-la na mão. Este mês (em outubro de 2011) uma mulher me chamou pra trabalhar com ela [...] pagava tudo. Só não fui porque tive pena, acredita? Deixar ela na mão perto do fim do ano, cheia de coisas pra fazer [...] não é que não goste dela, entendeu? Mas acho que ela explora muito [...]. (Roberta, 25 anos, empregada doméstica mensalista).

\footnotetext{
${ }^{3}$ Detive-me especificamente à investigação das profissionais já que elas (as mulheres) representam a grande maioria no setor.
} 
Virgínia Areias Pereira

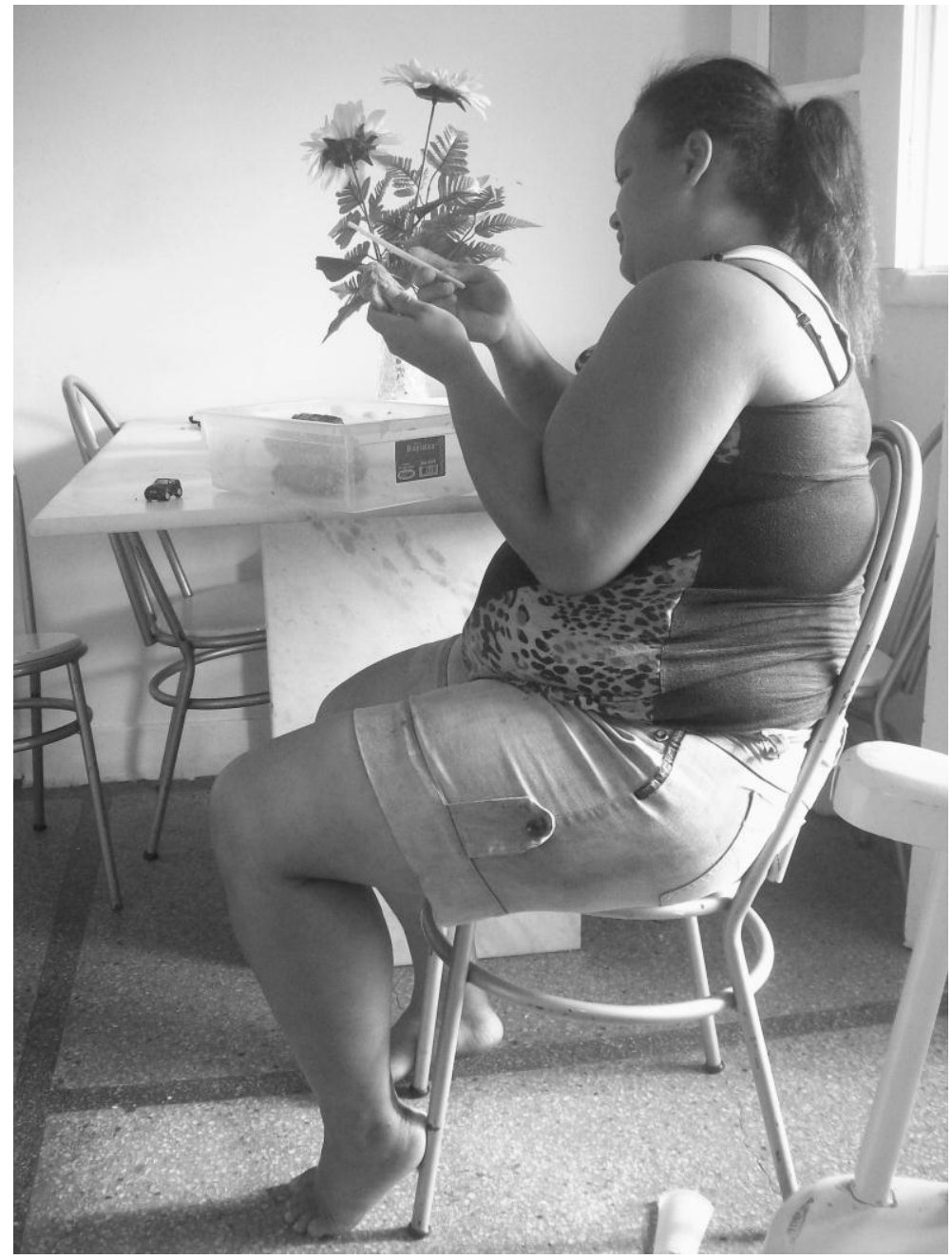

1. Roberta, 25 anos, empregada mensalista trabalhando. Foto de Virginia Areias Pereira, Recife, abril/2011. Acervo Virginia Areias Pereira.

O sentimento de Roberta, compartilhado de algum modo pela maioria das participantes, reflete as tensões imanentes a um universo intensamente contraditório (embora esta tensão esteja presente, em diferentes níveis, no mundo do trabalho em geral). Para ressaltar isso, é preciso dizer que as relações mais favoráveis apontadas pelas entrevistadas, são aquelas que asseguram o cumprimento dos direitos trabalhistas, mas ao mesmo tempo possibilitam os laços mais estreitos de amizade e as garantias de natureza informal como as concessões extraordinárias (negociações de folgas e presentes, por exemplo). Destaco outro depoimento para ilustrar essa discussão:

[...] por ela (a patroa) eu faço tudo. Ela é muito boa pra mim. Falto sempre que preciso, quando meus filhos adoecem... ela não desconta nada. Só pede que eu avise 
com antecedência quando eu posso (prever) que é para ela se programar, porque ela faz muitos plantões em hospitais, é médica... Ela é um anjo na minha vida, me dá de tudo, até o computador dos meninos foi ela quem deu... cuida deles quando adoecem, leva em hospitais quando o caso é sério... ela me fez voltar a estudar... Aí faço tudo por ela também... As outras (patroas) eram muito diferentes. Não me davam nada, não faziam nada por mim... (Joana, 38 anos, empregada doméstica mensalista).

Brites (2000) sugere, com toda a razão, que as relações que se desenvolvem entre patroas e empregadas, desvelam a manifestação plena da dádiva defendida por Mauss (1974), onde as trocas de presentes e agrados constituem parte fundamental para uma boa relação, mas contribuem também para as construções hierárquicas. Os achados empíricos de minha investigação corroboram a afirmação da autora e abrem caminhos para novas reflexões como as estratégias de aproximação e distanciamentos urdidas por essas trocas.

Desejei que meu trabalho significasse, antes, um espaço de manifestação para as profissionais. Privilegiei o registro mais preciso sobre a experiência do dia a dia sem perder de vista o contexto mais abrangente em que as tramas se desenvolvem. $\mathrm{O}$ investimento mais sistemático e criterioso exigido pelo campo surpreendeu meu espírito prevenido e abriu espaços para a reflexão acerca das mudanças sensíveis tanto no nível das subjetividades, quanto nos planos institucionais, num processo dialético permanente.

No entanto, não tenho o interesse de acionar todos os aspectos apresentados e discutidos no meu trabalho, neste momento. Quero, antes, e este é o propósito principal deste artigo, relatar (sem a preocupação com a exaustão) minhas incursões em campo, destacando principalmente algumas das experiências relacionadas aos registros fotográficos realizados com o consentimento das interlocutoras. Interessa-me, sobretudo, propiciar elementos para uma reflexão acerca das contribuições das fotografias, enquanto recurso metodológico, para enriquecer e direcionar o entendimento sobre as tramas que envolvem as relações de trabalho doméstico.

\section{Um modo de contar: registros e caminhos percorridos}

Meus primeiros contatos com as profissionais entrevistadas foram forjados numa teia de relações construídas a partir de algumas indicações iniciais. Havia, entre as participantes, três conhecidas: Claudete, Rosa e Lúcia, verdadeiros "elos" entre mim e as demais profissionais. Com o objetivo de desenhar os primeiros esboços sobre o tema, 
passei a encontrá-las com a frequência que era possível e sempre procurava abordar, em nossas conversas, um assunto relacionado ao serviço doméstico e às experiências pessoais de cada uma. Obviamente, explicava para minhas interlocutoras "familiares" e para todas as profissionais com quem estabeleci contato mais tarde, os meus interesses sobre o assunto (presentes e futuros).

Durante este período, minha motivação sobre o tema cresceu, pois a cada encontro me eram revelados aspectos de uma dinâmica que só reafirmava a minha relativa ignorância sobre o universo investigado. Desvelava-se diante de mim, não somente os problemas relacionados às formas de dominação e exploração conservadoras, tecidas num processo histórico-cultural particular, mas um complexo de ambivalências informadas por múltiplas frustrações e afetos.

Além disso, redesenhavam-se diante de mim figuras que desbotavam minhas noções estereotipadas e ilusórias. As mulheres mais jovens, por exemplo, afirmaram terem reduzido o número de filhos espontaneamente (ou mesmo evitado filhos) porque as responsabilidades típicas da maternidade limitavam ou dificultavam outras inserções, na visão delas. O emprego doméstico representava para essa parcela (mais jovem), uma atividade secundária e transitória diante do sonho e do investimento na busca de uma profissão mais socialmente valorizada. A multiplicidade de experiências esteve bastante associada à dimensão geracional e constituiu uma fonte preciosa para a reflexão sobre as transformações sociais.

Retomando os itinerários, posso dizer que as indicações, iniciadas com as primeiras entrevistadas, constituíram o fio condutor de minhas incursões em campo. No final, havia entrevistado quinze mulheres que se identificaram, alternadamente, como passadeira, diaristas, fixas (mensalistas), folguista, desempregada e ex-trabalhadora doméstica. Cada uma delas se mostrou muito receptiva e disposta a colaborar com a pesquisa, apesar do tempo livre, em geral, tão diminuto. Aliás, houve entusiasmo grande por parte delas - para contar suas histórias e se deixarem fotografar-, algo que me sensibilizou. Refletia sobre o que residia naquelas predisposições que me pareciam ir além da generosidade evidente.

Wacquant (2006) indicou um caminho para se pensar sobre isso, quando escreveu sobre as experiências de campo ${ }^{4}$ (sim, de campo) de Pierre Bourdieu. Fazer entrevistas e tirar fotografias das participantes era de fato uma forma de dizer, nas

\footnotetext{
${ }^{4}$ Realizadas na Argélia colonial e em sua aldeia natal no Béarn, sudoeste francês.
} 
palavras do referido autor, "estou preocupada com vocês, estou com vocês, estou ouvindo suas histórias, testemunharei sobre o que têm passado". A entrevista que captura experiências da vida diária tem uma função importante, como alerta Briggs (2007): fazer o invisível visível e quebrar o silêncio. Dar a chance de as pessoas expressarem seus sentimentos, de serem ouvidas.

O mesmo deve se dar com as imagens. A vontade de se apresentar, de dizer: "esta sou eu". Em sua ambígua e definitiva condição de documento/representação, as fotografias - enquanto processo que registra fragmentos do real sem escapar aos usos dirigidos (Kossoy, 2002) -, foram construídas por mim em parceria. Não somente em virtude do consentimento das participantes, mas pela cumplicidade evidenciada nos entusiasmos frente aos registros (orais e escritos) e nas escolhas e sugestões para realizá-los.

Bittencourt (1998) argumenta que, de modo restrito, "nos trabalhos etnográficos, o material visual é apresentado como um apêndice do texto escrito, que domina a forma de representação do conhecimento antropológico servindo para dar autoridade e realismo ao relato etnográfico". De fato, as imagens coletadas em pesquisa de campo podem ser utilizadas como pontes que relacionam os dados à tradição oral e à memória dos grupos estudados. Fui definitivamente movida, em boa medida, por este caminho metodológico. 




2. Marília, 56 anos, passadeira, chega em casa depois de mais um dia de serviço. Foto de Virginia Areias Pereira, Recife, maio/2011. Acervo Virginia Areias Pereira.

A ideia do registro fotográfico veio depois das duas primeiras histórias colhidas. Tanto que precisei encontrar essas participantes para sugerir os registros. O fato é que as elaborações realizadas a partir dos depoimentos evocavam imagens, manifestavam, como um imperativo, a necessidade de "personificar as oralidades", para utilizar as palavras de Souza (2012), e capturar fragmentos da realidade. Portanto, investi, sem dúvida, num esforço para tentar suturar a narrativa à dimensão palpável da imagem.

Quanto à memória, percebo que o apreço pelo "guardar" constituiu uma especial motivação para meu interesse em fotografar as participantes da pesquisa. Guardar no sentido de zelar, observar, preservar, como foi dito anteriormente. Captar um cenário, em sentido pleno e articulado a dimensões mais abrangentes representava uma atitude que não só permitia tornar visíveis as atrizes implicadas, mas zelar por uma mensagem.

Quero dizer com isso que, para mim, cada entrevistada encerrava em si uma mensagem que, de maneira geral, articulava e nutria a própria narrativa do grupo. São gestos e expressões, hábitos e posturas, que de modo algum escapam à interpretação do 
espectador, mas impressionam por representarem fontes inesgotáveis para a reflexão. O exposto lembrou-me da experiência com uma das entrevistadas: Cristina.

Durante o depoimento, Cristina fazia questão de reforçar a sua condição de desempregada. Dizia isso com evidente orgulho ao explicar que parte dessa situação, devia-se ao fato de que ela mesma era muito exigente quanto às condições de um acordo de trabalho. Afirmava, entre outras coisas, que não trabalhava aos sábados e que uma carga horária predefinida (em torno de seis a oito horas darias de trabalho) representava item fundamental para que ela aceitasse uma oferta: "não quero trabalhar sem hora pra largar por causa do meu filho e porque não acho justo mesmo [...]”, explicava.

No final da entrevista perguntei a Cristina se poderia tirar uma foto dela. Ela consentiu com certo entusiasmo que se repetia neste momento, de modo geral, entre as participantes. Mas houve um fato curioso, desta vez. Ao conferir a foto (na máquina digital), a entrevistada disse que não havia se agradado. O motivo: "estou com cara de desempregada mesmo", disse aos risos. Perguntei o que isso queria dizer e ela afirmou que se tratava da aparência desleixada e "desocupada". Através desta ideia, pude perceber o lugar especial que o trabalho ocupava na vida de Cristina, apesar de algumas frustrações relatadas. Estar ativa era uma condição preliminar para a boa aparência, era um motivo para os cuidados pessoais. Quis saber se a entrevistada gostaria de desistir da foto. Disse que não e pediu-me um instante para "se arrumar". Voltou de cabelos soltos e calça jeans (vestia uma saia antes disso). Fiz então alguns registros e Cristina apontou a foto "permitida", aquela que depois seria apresentada em minha dissertação. 


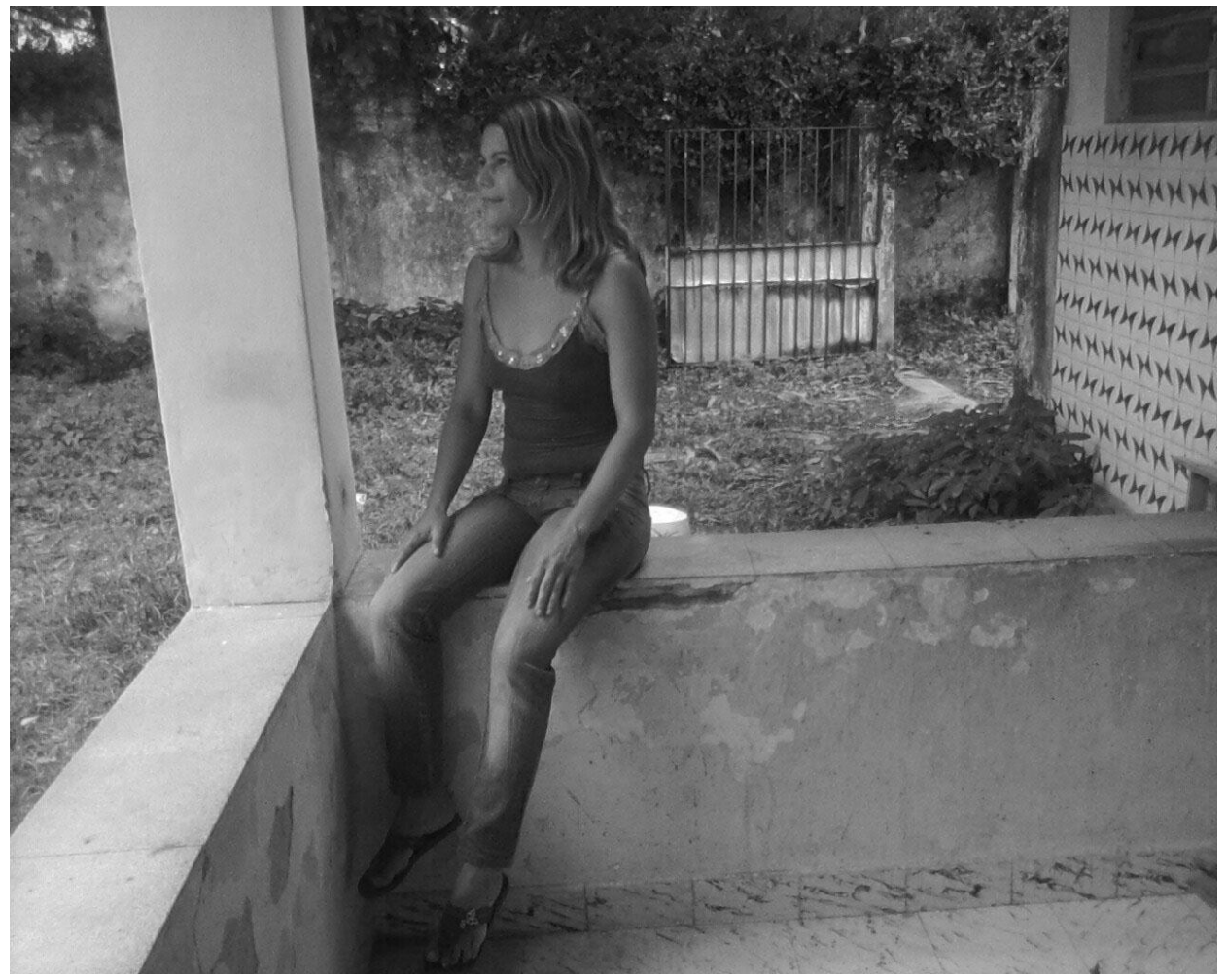

3. Cristina, 40 anos, trabalhadora doméstica desempregada. Foto de Virginia Areias Pereira, Recife, outubro/2011. Acervo Virginia Areias Pereira.

Faz-se necessário um esclarecimento aqui. Uma forma que encontrei para utilizar as fotografias foi oferecendo às entrevistadas a oportunidade de sugestão e seleção entre alguns registros. Porém, propus o recurso a uma relativa "manifestação anônima", apesar dos consentimentos. Desse modo, foram privilegiados planos de tomada calculados por esta preocupação. Para mim tratava-se antes do respeito e da ética no trato com questões tão delicadas. Em muitos momentos os depoimentos evocavam situações complicadas marcadas por traição, separação, humilhação, frustração, entre temas de foro tão íntimo.

Depois, eu não tive interesse em recorrer aos termos de consentimento (formalizar as permissões) porque havia gostado muito do resultado das primeiras fotografias. No meu entendimento os registros alcançaram uma forma estética delicada de expressão que se ancorava, ao mesmo tempo, na "revelação" e no "ocultamento". Noutras palavras, essa forma permitia a personificação das oralidades, sem, contudo, romper com aquela delicadeza. Portanto, foi uma omissão pensada que, além de permitir o cuidado devido, provocava o desejo da decifração. Mas não é disso que se 
constituem as fotografias? Elas não são plenas de ambiguidades (Kossoy, 2002) e de segredos? Pois não contamos tudo para ninguém, nem para nós mesmos! (Piñon, 1997). Tive o apoio das entrevistadas, e houve consenso, quanto às razões que deram sentido ao o recurso aplicado.

A relação entre pesquisador (a) e entrevistado (a) deve ser alicerçada pela honestidade, respeito e confiabilidade. O trabalho etnográfico não pode ser realizado a qualquer custo, há um limite, especialmente quando solicita o desvelamento de aspectos tão íntimos e delicados das vivências dos sujeitos e propõe o registro de imagens. A pesquisa, entendo, é desenvolvida a partir de parcerias, do tempo delicadamente negociado, de informações gentilmente concedidas, de espaços construídos como meio de expressão. No caso de Cristina, o registro fotográfico foi orientado pela vontade da participante e ancorava-se num aspecto emocional evidente, no pacto selado não com a "revelação", mas com o "ocultamento" de uma condição desfavorável: a "desocupação", em suas palavras.

Comungando com as ideias de Wacquant (2006), reviso e ressalto as funções que as fotografias desempenharam em meu trabalho. Primeiro, elas representaram uma técnica eficiente para o armazenamento ou, noutras palavras, para a guarda e eternização de momentos fundamentais em minha trajetória em campo, como afirmei noutro lugar. Momentos forjados pelo encontro. Cada imagem remete a um itinerário que se iniciava com uma indicação, levava a buscas pelo contato e possíveis agendamentos e, finalmente, ao encontro que se realizava em lugar sempre definido pelas profissionais: espaços públicos, local de trabalho, suas próprias residências.

Os registros fotográficos ajudaram também a reforçar fragmentos da narrativa, restaurando o elo entre o sujeito da imagem e as falas captadas nos depoimentos. Neste sentido, as fotografias representaram um recurso que contribuiu para a "personificação das oralidades" e para a restauração de uma trama a partir do encontro etnográfico. Destaco um dos casos, para esta reflexão. Claudete, ex-trabalhadora doméstica, resaltou, em muitos instantes da entrevista, a importância da mudança de ocupação para ela.

A entrevistada, que já havia trabalhado para mais de quatro famílias, se encontrava em nova ocupação, trabalhava há quase um ano como auxiliar de limpeza numa grande academia de ginástica. Assim como Marília, passadeira, e outras profissionais que relacionaram o vínculo diarista ao sentimento de autonomia (autogestão das tarefas e do tempo), Claudete também atribuiu um sentido positivo à nova função, no que tange à visibilidade e ao reconhecimento pleno dos direitos. No 
meu entender, a imagem de Claudete reforça a sensação de movimento da narrativa oral, leva a uma espécie de conexão com a dimensão temporal acentuando a ideia de "rompimento" com o passado e restaurando o tempo presente ou a experiência atual.

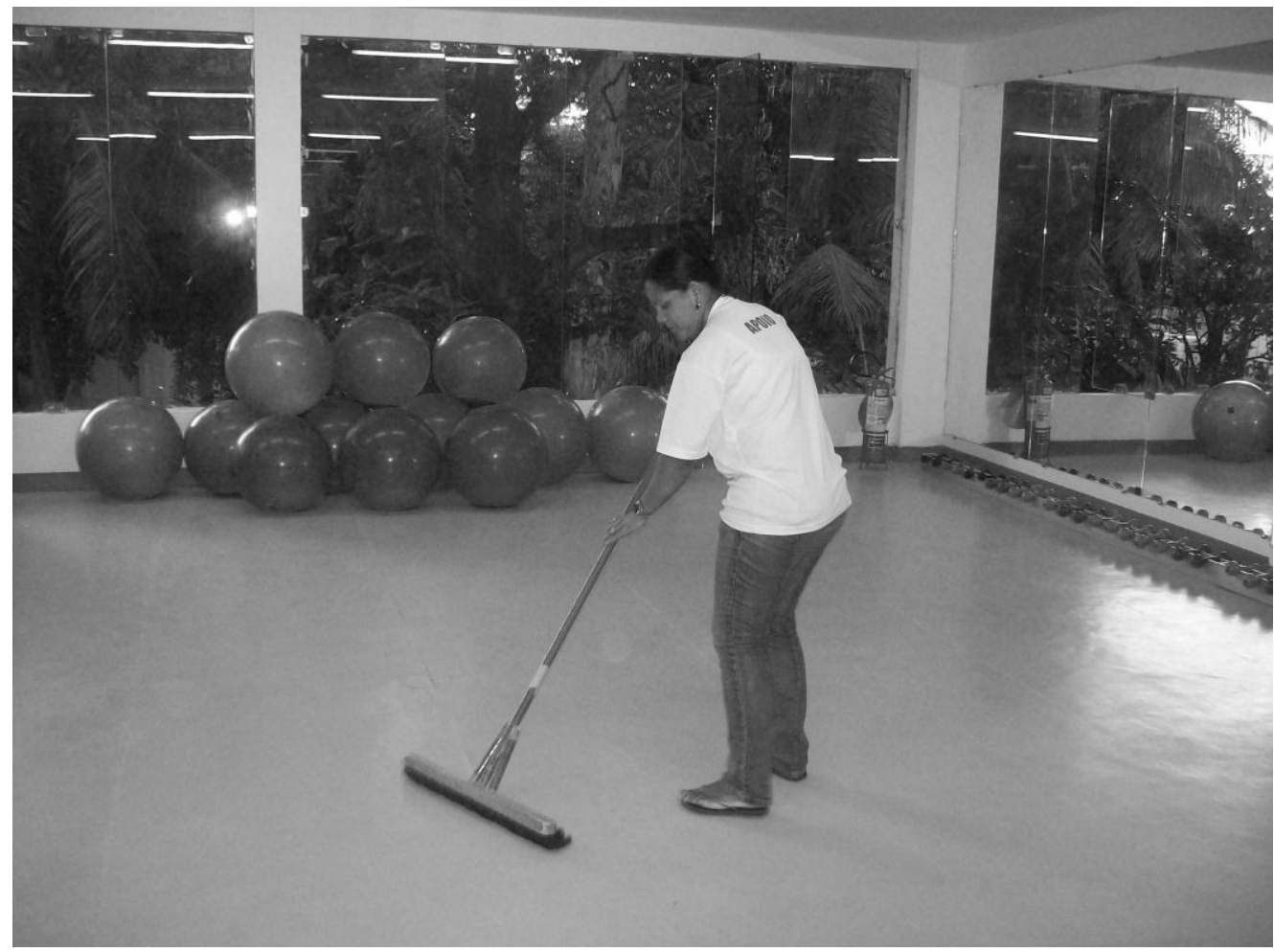

4. Claudete, 36 anos, em nova ocupação. Foto de Virginia Areias Pereira, Recife, abril/2011. Acervo Virginia Areias Pereira.

Os registros auxiliaram-me ainda a lidar com o estado de "aproximação afetiva" com o tema, o que nos remete, de certo modo, ao início deste texto, às considerações de Damatta (1987). Neste caso, os instrumentos utilizados para as captações (orais e imagéticas) davam-me (ou lembravam-me constantemente) de um dever concreto: estabelecer um esforço para buscar "o distintivo olhar da etnografia não apenas na colônia distante, mas também num universo familiar ou familial" (Wacquant, 2006), desarmando o espírito prevenido, demasiadamente convencido de suas prenoções acerca do mundo investigado.

Sensibilizar e aguçar o olhar, esta foi uma preocupação constante para mim. Uma das participantes, Rosa - uma velha conhecida de minha família e pessoa próxima 
POR UM CLICK...

a mim-, estabeleceu que nosso reencontro ${ }^{5}$ se daria no local de trabalho dela. Acostumada a vê-la, nos últimos tempos, durante o trajeto de sua chegada ou saída do serviço, fiquei de certo modo surpresa quando fui recebida por "aquela mulher" vestida em traje típico e costumeiro (uniforme branco, avental e lenço na cabeça), segurando uma vassoura. Cheguei a pensar, por um breve instante, que aquela cena era proposital. Rosa estaria "metamorfoseada" para a minha chegada! Entretanto, Ela me pediu gentilmente um instante, precisava concluir um serviço. Estava trabalhando, afinal.

Os adornos típicos de um vínculo mais tradicional de trabalho demarcavam o lugar de Rosa naquela casa e contribuía para a minha adoção de uma postura relativamente distanciada, sem que isso, obviamente, pudesse ser capaz de dissolver minha proximidade com ela. Quis saber como Rosa queria ser fotografada, no final do serviço que realizava. Ela respondeu: “pode tirar assim, se você quiser...”. Em depoimento, Rosa se queixou principalmente das longas jornadas e do peso associado ao tipo de trabalho (arrumação, cozinha, limpeza de quintal). A fotografia de Rosa, para mim, concentra num espaço visual restrito, uma forma de sobrevivência e contribui para desvelar o mundo simbólico ao qual o traje se liga. Um mundo privado com demarcações indissolúveis pelas afetividades.

\footnotetext{
${ }^{5}$ Para fazer o registro fotográfico, uma vez que a entrevista com Rosa já havia sido realizada em minha própria casa, local sugerido pela trabalhadora.
} 


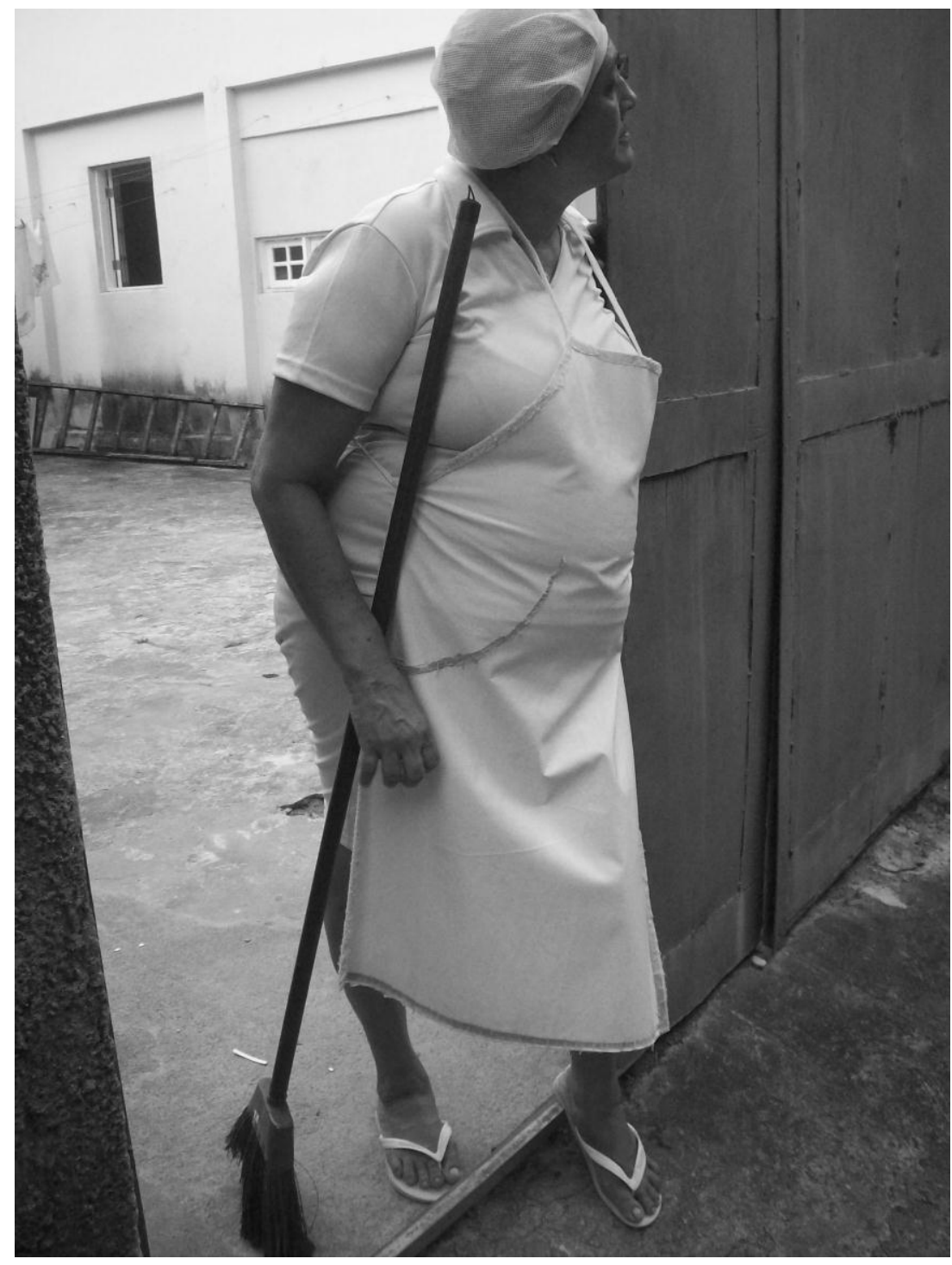

5. Rosa, 51 anos, empregada mensalista em dia de trabalho. Foto de Virginia Areias Pereira, Recife, julho/2011. Acervo Virginia Areias Pereira.

Para finalizar, é preciso esclarecer que minhas intenções neste momento não foram a de esgotar as experiências vivenciadas com cada uma das participantes, entrevistadas e fotografadas para minhas elaborações. Mesmo porque, todos os registros encontram sentido nas razões aqui apresentadas: elo entre narrativa escrita e oralidades, captação de um "microaspecto de um contexto" (Kossoy, 2002), preservação do encontro etnográfico e recurso precioso para reforçar o meu papel enquanto pesquisadora, conservando ao mesmo tempo uma proximidade inevitável e absolutamente saudável com as interlocutoras. 


\section{Considerações Finais}

O estudo sobre o emprego doméstico e as profissionais me proporcionou vivenciar algumas tramas veladas marcadas por vínculos variados, mas uniformes nas suas ambivalências, contradições indissociáveis. Tive acesso a uma gama de informações que reafirmaram a ideia defendida por Damatta (1987), de que o familiar não é necessariamente conhecido. Posso dizer que o mundo que despontava diante de mim guardava sutilezas que "iludiam" o olhar habituado. Cabe ao cientista social trazer a lume compreensões da realidade tácita que, na maioria das vezes, passa aos olhos de maneira despercebida.

Por outro lado, a amizade com algumas mulheres, como disse noutro lugar, representou um facilitador para minha inserção numa teia de relações que viria a ser a própria base de minha pesquisa empírica, o alicerce das minhas elaborações. A boa receptividade do (a) interlocutor (a) é um critério fundamental para a riqueza do estudo. O fato de eu chegar a cada participante por meio da indicação de uma amiga dessa, certamente produziu algum efeito em termos de cumplicidade e "desembaraço" úteis à pesquisa. No meu entendimento, o desafio é manter a proximidade, indissociável do que somos e levamos conosco, permitindo um distanciamento eficaz para as observações.

Um dos recursos que me auxiliaram neste exercício, foi à utilização de registros fotográficos em minhas pesquisas, além dos registros orais. Essas técnicas combinadas com a qualidade da escuta contribuíram para o aproveitamento pleno das oportunidades que o campo ofereceu. Quanto às pretensões, é justo dizer que existe sempre uma motivação interior ou exterior para a criação de uma fotografia (Kossoy, 2002), e como não podia deixar de ser, a minha intencionalidade influenciou fortemente a minha concepção e construção das imagens.

Retomando o que foi dito, as fotografias tiveram algumas funções primordiais. Duas delas se relacionam diretamente com o texto elaborado. Primeiro, de modo estrito e subordinado, busquei nas imagens um apêndice para as narrativas escritas, por meio das representações imagéticas. Por outro lado, os registros consistiram numa atividade complementar em relação ao texto, uma vez que contribuíram para "personificar as oralidades", as falas colhidas. Recursos como o ocultamento parcial das imagens ou, noutras palavras, a "manifestação relativamente anônima" dessa personificação, representou para mim um modo de evitar exposições desnecessárias já que a pesquisa 
envolvia temas delicados como estigmatização, frustrações, relatos sobre a vida mais íntima e privada, entre outros assuntos.

Outra função importante que tiveram os registros fotográficos, para mim, foi a possibilidade de cristalização de um momento, a perpetuação do encontro, enfim, o registro de um fragmento do real: parte dos sujeitos implicados na relação de trabalho. Portanto, refiro-me a um guardar no sentido de zelar e preservar aquilo que se deseja rever, imobilizar e reviver. Contudo, não escapo à sedução das evidências e as imagens fotográficas representaram um testemunho dos caminhos percorridos, do rastro indicial, para utilizar as palavras de Kossoy (2002), das minhas incursões nos terrenos do emprego doméstico. Um lugar marcado por profundas ambiguidades como é a fotografia, que além de congelar a flecha do tempo, como pontua Prigogine (1996), permite a todos, que assim desejarem, estudar o campo hoje cristalizado por mim, prova de que a fotografia, notadamente conhecida como recurso artístico por excelência, também pode servir como documento sócio-histórico e elemento reflexivo para entender a condição humana, que talvez, como aponta Lévi Strauss, seja a tarefa maior da antropologia.

\section{Referências}

ALAMI, Sopfhie; DESJEUX, Dominique; GARABUAU-MOUSSAOUI, Isabelle. Os Métodos Qualitativos. Rio de Janeiro: Vozes, 2010.

BRIGGS, Charles. "L. Anthropology, Interviewing, and Communicability". In: Contemporary Society. Current Anthropology, v.48, n.4. August 2007. Chicago: The University of Chicago Press, 2007.

BRITES, Jurema. "Afeto e desigualdade: gênero, geração e classe entre empregadas domésticas e seus empregadores". In: Cadernos Pagu, v 29, julho-dezembro, 2007. Campinas: UNICAMP. p. 91-109.

BITTENCOURT, Luciana A. Algumas considerações sobre o uso da imagem fotográfica na pesquisa antropológica. In: BIANCO-FELDMAN, Bela; LEITE Míriam L. M (orgs.). Desafios da Imagem: fotografia, iconografia e vídeo nas ciências sociais. São Paulo: Papirus, 1998.

DAMATTA, Roberto. Relativizando. Rio de Janeiro: Editora Rocco LTDA, 1987.

FRANCO, Maria Sylvia C. F. Homens livres na ordem escravocrata. São Paulo: Fundação Editora da UNESP, 1997.

FREYRE, Gilberto. Casa Grande e Senzala: introdução à história da sociedade patriarcal no Brasil. Rio de janeiro: Livraria José Olympio Editora, 1967.

GRAHAM, Sandra Lauderdale. Proteção e obediência, criadas e seus patrões no Rio de Janeiro 1860 - 1910. São Paulo: Companhia das Letras, 1992. 
KOSSOY, Boris. Realidades e Ficções na Trama Fotográfica. São Paulo: Ateliê Editorial, 2002.

KUPER, Adam. A Visão dos Antropólogos. Bauru - São Paulo: EDUSC, 2002.

MAUSS, Marcel. "Ensaios sobre a Dádiva: força e razão da troca nas sociedades arcaicas". In: Sociologia e Antropologia. São Paulo: EPUD/EDUSP, 1974.

MOORE, Henrietta. A Passion for Difference: Essays in Anthropology and Gender. Cambridge: Polity Press; Oxford: Blackwell, 1994.

SENNETT, Richard. Autoridade. Rio de Janeiro: Record, 2001.

SOUZA, Luciano B. Guardião do Maracatu Leão Coroado: uma coisa de deixa. 2012. Dissertação (Mestrado em Antropologia) - Centro de Filosofia e Ciências Humanas Universidade Federal de Pernambuco, Recife, 2012.

PEREIRA, Virgínia A. Herança escravocrata e trabalho doméstico remunerado: rupturas e permanências. 2012. Dissertação (Mestrado em Antropologia) - Centro de Filosofia e Ciências Humanas - Universidade Federal de Pernambuco, Recife, 2012.

PIÑON, Nélida. A doce canção de Caetana. São Paulo: Record, 1997.

PRIGOGINE, Ylia. O Fim das Certezas: tempo, caos e as leis da natureza. São Paulo: Fundação Editora da UNESP (FEU), 1996.

WACQUANT, Loïc. "Seguindo Pierre Bourdieu no campo". In: Rev. Sociol. Polít. n.26, jun. 2006. Curtitiba: UFPR, 2006. p. 13-29.

Recebido em: 31/10/2012

Aprovado em: 15/12/2012 